\title{
A Comment on the Paper: Were the First Europeans Pale or Dark Skinned? (by C. Winters, Advances in Anthropology, 2014, 4, 124-132)
}

\author{
Anatole A. Klyosov \\ Editor-in-Chief, Advances in Anthropology \\ Email: aklyosov@comcast.net
}

Received 29 September 2014; revised 24 October 2014; accepted 18 November 2014

Copyright (C) 2014 by author and Scientific Research Publishing Inc.

This work is licensed under the Creative Commons Attribution International License (CC BY). http://creativecommons.org/licenses/by/4.0/

(c) () Op Och Access

\begin{abstract}
This comment considers a paper by C. Winters recently published in Advances in Anthropology, as well as some of his related papers, concerning the "origin of haplogroup R1 in Africa", "Neanderthals originated in Africa", "Neanderthals spread from Morocco to East Africa", "the Cro-Magnon people were probably Bushman/Khoisan", and other inventions which do not belong to this Journal.
\end{abstract}

\section{Keywords}

\section{Haplogroups, Haplotypes, R1b, Neanderthals, Pygmy, DNA Genealogy}

The cited paper (Winters, 2014) has avoided, unfortunately, an approval by the Editor-in-Chief, and slipped through to the Journal. The problem is that the paper contains several wrong and many highly questionable statements. As it happens with some authors, they selectively cite some references, often placing quotes out of context, ignore other references and data, which contradict their views. The above is a brief description of the cited article that is grossly misleading.

Overall, the paper represents a collection of assorted quotations and declarations, many of them without any link to the title and/or the main subject of the paper. Most of declarations do not have links to any scientific reference, many of them reflect certain confusions, some references and data are taken out of context and described in a distorted manner.

Here is a typical example of the author's style and reliability of quotations. In his preceding paper, entitled “Possible African origin of Y-chromosome R1-M173” (Winters, 2011), the author writes: “The Khoisan also 
carry RM343 (R1b)... (Naidoo et al., 2010) the archaeological and linguistic data indicate the successful colonization of Asia by Sub-Saharan Africans from Nubia 5 - 4 kya". If the reader looks up at the Naidoo et al. paper, it shows that the great majority of R1b-M343 haplotypes were found among South African Whites (81 out of 157), while Khoe-san contain three R1b-M343 haplotypes out of 183. Mr. Winters did not even mention such a discrepancy, which brings a different angle at the data.

Here is another example. In the same paper (Winters, 2011) he writes on "widespread distribution of $R 1{ }^{*}$ M173 in Africa, that ranges between 7\% - 95\% and averages 39\% (Coia et al., 2005)”. He repeats the same "quotation" in yet another paper (Winters, 2010)—“The frequency of Y-chromosome R $1{ }^{*}$-M173 in Africa range between 7\% - 95\% and averages 39.5\% (Coia et al., 2005)". However, in the referenced paper Coia et al. (2005) describe the frequency of R1*-M173 only in Cameroon, "with the highest frequency in North Cameroon (from $6.7 \%$ among the Tali to $95.2 \%$ among the Uldeme". Mr. Winters did not mention that the figures were related not to "widespread distribution in Africa", but specifically to North Cameroon, which is known since at least 2002 (Cruciani et al., 2002, 2010). In the same manner Mr. Winters "quote” data by Berniell-Lee et al. (2009), who had reported that $5.2 \%$ of R1b1* were identified in Cameroon and neighboring Gabon, and "quote" it as follows "Haplogroup R1b1* is found in Africa...Berniell-Lee et al. (2005) found in their study that $5.2 \%$ carried $R b 1 *$ " (spelling by Winters, 2011). As one sees again, Cameroon and Gabon were not mentioned, only "found in Africa $5.2 \%$...”.

Here is yet another example. According to Winters (2011), "The bearers of R1b1* among the Pygmy populations ranged from 1\% - 25\% (Berniell-Lee et al., 2009)”. In fact, Figure 1 in the Berniell-Lee et al. paper shows only two individuals having R1b1*, one from Baka tribe (out of 33 tested) in Gabon, and one from Bakola tribe (out of 22 tested) in Cameroon. So much for $1 \%-25 \%$. The list of misquotations can go on. That was a basis for the "African origin of R1-M173".

Let us review an "age" of the R1b1* lineages in Cameroon and Gabon, based on haplotypes listed in (Berniell-Lee et al., 2009). Figure 1 shows a haplotype tree, which is split into two distinct branches, on the leftand right-hand sides.

The right-hand side branch coalesces to the base (deduced ancestral) haplotype:

13241511131612131413161411121211111211

All 27 haplotypes of the branch contain 81 mutations from the base haplotype. It gives 81/27/0.0243 = $123 \rightarrow$ 141 conditional generations (of 25 years each, see Klyosov, 2012); that is $3525 \pm 530$ years from a common ancestor of the branch. Here the arrow shows a correction for back mutations (Klyosov, 2009, 2012), the margin of error calculated as described in (Klyosov, 2009).

The left-hand side branch has the following base haplotype:

12241510131512121412141410121211111211

All 19 haplotypes of the branch contain 46 mutations. It gives 46/19/0.0243 $=100 \rightarrow 111$ conditional generations, that is $2775 \pm 495$ years from a common ancestor of the branch. One can see that the two populations could have migrated to Gabon about the same time (within the margin of error of the calculations), in the I-II millennium BC, and that time was not, of course, the time of "origin" of haplogroup R1. The latter arose around 26,000 years ago, in Central Asia, apparently in South Siberia (Klyosov, 2012). Indeed, an excavated haplogroup R was recently identified in South Siberia (near the lake of Baikal), with an archaeological date of 24,000 years ago (Balter, 2013; Raghavan et al., 2013).

In the same manner and style of misquotations and distorted "information", Mr. Winters continues in his latest paper in Adv. Anthropol. (2014). He writes in the beginning of the paper-"Klyosov claims that the first Europeans were fair (pale) skin", and "Klyosov argued that...ancient Europeans were fair (pale) skin and that most African haplogroups were the result of a back migration of pale skinned Europeans". However, this is not the case in the paper (Klyosov, 2014). The words "Europeans" and "skin" are never used in the paper next to each other, or in any other combination. There is nothing in the paper (Klyosov, 2014) regarding skin color of Europeans. There is nothing in the paper about "back migration of Europeans" to Africa, let alone "pale skinned Europeans". Those are all inventions of Mr. Winters.

In other words, the paper (Klyosov, 2014) has nothing to do with the title of Mr. Winters article- "Were the first Europeans pale of dark skinned?” Apparently, Mr. Winters was seriously confused. However, Mr. Winters has made several other statements, some of them worth consideration in this Comment; seven of them are as follows:

1) “Archaeological evidence indicated that Neanderthals originated in Africa” (no reference given). 


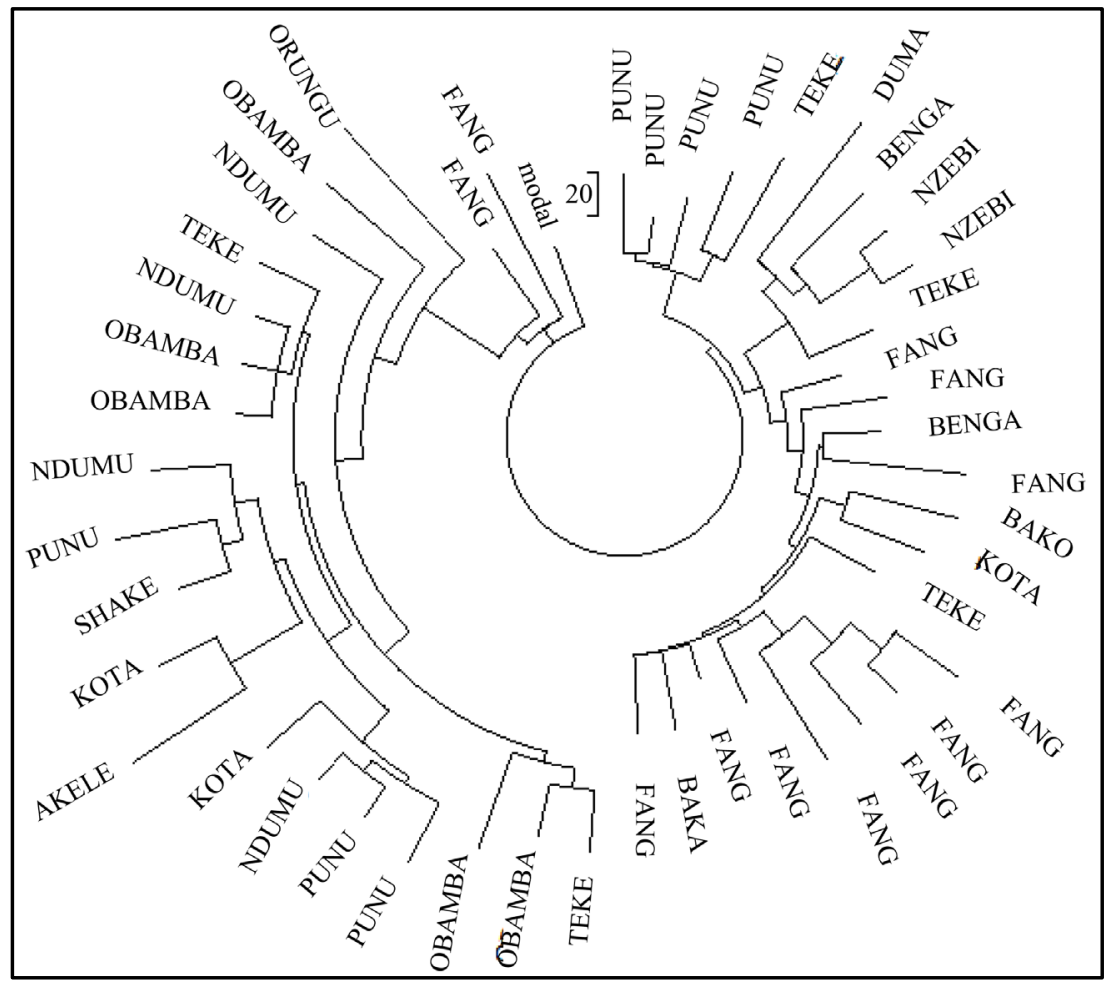

Figure 1. The tree is composed of 46 of 19-marker haplotypes of haplogroup R1b1*, 44 of them from Gabon, and two (the Pygmy individuals) from Cameroon (both are on the right-hand side). The haplotype tree was composed using software PHYLIP, Phylogeny Inference Package program (Felsenstein, 2004) and MEGA, Molecular Evolutionary Genetics Analysis, Version 6.0 (Tamura et al., 2013). The haplotypes employ the following markers: DYS 393, 390, 19, 391, 385a, 385b, 388, 439, 389-1, 393, 389-2, 437, 460, 438, 436, 462, 434, 461, 435.

2) "Between 139 and 125 kya the Neanderthals migrated back into Africa and spread from Morocco to East Africa (Ki-Zerbo, 1981: p. 572)".

3) "The archaeological, anthropological and genetic evidence indicated that the first Europeans were dark skin Sub-Saharan Africans" (no reference given).

4) "Sub-Saharan Africans...carried Y-chromosome C6 into Europe" (no reference given).

5) "The archaeological research makes it clear Neanderthal probably mixed with Africans" (no reference given).

6) “The Cro-Magnon people were probably Bushman/Khoisan (Boule \& Vallois, 1957)”.

7) "The archaeological and craniometric evidence indicates that the pre-Indo-European people were probably highly pigmented" (no reference given).

Let me explain:

Item 1. I would be delighted to learn of that "archaeological evidence", that "Neanderthals originated in Africa". However, alas, there was no reference provided. On the contrary, there are sufficient references that essentially repeat this: "Neanderthals, Homo Neanderthalensis, lived between 350,000 and 24,500 ya, throughout Europe and the Middle East, but...no Neanderthals fossils have yet been found in Africa" (Fuerle, 2008).

Here is an another quotation, from a paper on genome studies: "Our analysis of human-Neandertal data...confirms previous claims that Neandertals contributed genetically to contemporary Eurasian populations (Green et al., 2010; Sankararaman et al., 2012; Yang et al., 2012). However, in contrast to previous studies we can conclusively reject long-term population structure in the ancestral African population as an alternative explanation for the excess sharing of derived mutations by Neandertals and Eurasians" (Lohse \& Frantz, 2014).

Since Mr. Winters often cites the book "Fossil Men" by Boule and Vallois (1957), it would be appropriate to note that in the sizeable chapter "Neandertal Man" (pp. 193-258) the word "Africa" is mentioned only once, in 
the Conclusions section, in a negative context, that Neanderthals are "very different...from the Eskimoes, the Fuegians, the Bushmen, the Pygmies, African or Asiatic, the Veddas, the Polynesians, the Melanesians, and even from the Australians, with whom attempts at comparison have often been made" (p. 252).

Item 2. Comments in Item 1 show that "spread from Morocco to East Africa" for Neanderthals after "between 139 and 125 kya" is not supported by any archaeological or other data.

Item 3. The archaeological and anthropological" evidence cannot witness the "dark skin" color of "the first Europeans", much less that they were "Sub-Saharan Africans". No wonder that no reference was provided. Regarding genetic data, all that they have shown is that "both Loschbour and Stuttgart had dark hair...and Loschbour, like La Braña and Motala12, probably had blue or light colored eyes...whereas Stuttgart probably had brown eyes. Neither Loschbour nor La Braña carries the skin-lightening allele in SLC24A5...” (Lazaridis et al., 2014). They were not "the first Europeans", they lived 7000 - 8000 ya. Regarding the first Europeans, there is no genetic data available, and archaeological data on excavated bones do not (and cannot) say anything on their skin color.

Item 4. There is no data that haplogroup/subclade C6 was brought to Europe by "Sub-Saharan Africans". No wonder that a reference was not provided.

Item 5. There is no archaeological research which "makes it clear" that "Neanderthal probably mixed with Africans". Neither "clear", nor "probably". Genetics does not show such a connection (Vernot \& Akey, 2014; Reyes-Centeno et al., 2014; Sankararaman et al., 2014; Lohse \& Frantz, 2014).

Item 6. The statement that "The Cro-Magnon people were probably Bushman/Khoisan" cannot be considered seriously without more direct data than a reference related to 1915 as "Peringuey has told us that in certain burials on the South African coast 'associated with the Aurignacian or Solutrean type of industry" (Boule \& Vallois, 1957: p. 319).

Item 7. There is no "archaeological and craniometric evidence" that can possibly indicate that "the pre-Indo-European people were probably highly pigmented". Again, no wonder that a reference was not provided.

Indeed, the paper by Winters (2014) is grossly misleading.

\section{Acknowledgements}

The author thanks Susan Hedeen for her valuable help with the preparation of the manuscript.

\section{References}

Balter, M. (2013). Ancient DNA links Native Americans with Europe. Science, 342, 409-410. http://dx.doi.org/10.1126/science.342.6157.409

Berniell-Lee, G., Calafell, F., Bosch, E., Heyer, E., Sica, L., Mouguiama-Daouda, P., van der Veen, L., Hombert, J.-M., et al. (2009). Genetic and Demographic Implications of the Bantu Expansion: Insights from Human Paternal Lineages. Molecular Biology and Evolution, 26, 1581-1589. http://dx.doi.org/10.1093/molbev/msp069

Boule, M., \& Vallois, H. V. (1957). Fossil Men. The Dryden Press, New York, 535 p.

Coia, V., Destro-Bisol, G., Verginelli, F., Battagia, C., Boschi, I., Cruciani, F., Spedini, G., Comas, D., \& Calafell, F. (2005). Brief Communication: mtDNA Variation in North Cameroon: Lack of Asian Lineages and Implications for Back Migration from Asia to Sub-Saharan Africa. American Journal of Physical Anthropology, 128, 678-681.

http://dx.doi.org/10.1002/ajpa.20138

Cruciani, F., Santolamazza, P., Shen, P., Makaulay, V., Moral, P., Olckers. A., Modiano, D., Holmes, S., et al. (2002). A back Migration from Asia to Sub-Saharan Africa Is Supported by High-Resolution Analysis of Human Y-Chromosome Haplotypes. The American Journal of Human Genetics, 70, 1197-1214. http://dx.doi.org/10.1086/340257

Cruciani, F., Trombetta, B., Sellitto, D., Massaia, A., Destro-Bisol, G., Watson, E., Colomb, B. E., Dugoujon, J. M., Moral, P., \& Scozzari, R. (2010). Human Y Chromosome Haplogroup R-V88: A Paternal Genetic Record of Early Mid Holocene Trans-Saharan Connections and the Spread of Chadic Languages. European Journal of Human Genetics, 18, 800-807. http://dx.doi.org/10.1038/ejhg.2009.231

Felsenstein, J. (2004). PHYLIP (Phylogeny Inference Package). Seattle, WA: Department of Genome Sciences, University of Washington.

Fuerle, R. D. (2008). Erectus Walks among Us. New York: Spooner Press, 340 p.

Green, R. E., Krause, J., Briggs, A. W., Maricic, T., Stenzel, U., et al. (2010). A Draft Sequence of the Neanderthal Genome. Science, 328, 710-722. 
Klyosov, A. A. (2009). DNA Genealogy, Mutation Rates, and Some Historical Evidences Written in Y-Chromosome. I. Basic Principles and the Method. Journal of Genetic Genealogy, 5, 186-216.

Klyosov, A. A. (2012). Ancient History of the Arbins, Bearers of Haplogroup R1b, from Central Asia to Europe, 16,000 to 1500 Years before Present. Advances in Anthropology, 2, 87-105. http://dx.doi.org/10.4236/aa.2012.22010

Klyosov, A. A. (2014). Reconsideration of the "Out of Africa” Concept as Not Having Enough Proof. Advances in Anthropology, 4, 18-37. http://dx.doi.org/10.4236/aa.2014.41004

Lazaridis, I., Patterson, N., Mittnik, A., Renaud, G., Mallick, S., Kirsanow, K., Sudmant, P. H., Schraiber, J. G., et al. (2014) Ancient Human Genomes Suggest Three Ancestral Populations for Present-Day Europeans. Nature, 513, 409-413. http://dx.doi.org/10.1038/nature13673

Lohse, K., \& Frantz, L. A. F. (2014). Neandertal Admixture in Eurasia Confirmed by Maximum-Likelihood Analysis of Three Genomes. Genetics, 196, 1241-1251. http://dx.doi.org/10.1534/genetics.114.162396

Naidoo, T., Schlebusch, C. M., Makkan, H., Patel, P., Mahabeer, R., Erasmus, J. C., \& Soodyall, H. (2010). Development of a Single Base Extension Method to Resolve Y Chromosome Haplogroups in Sub-Saharan African Populations. Investigative Genetics, 1, 1-11. http://dx.doi.org/10.1186/2041-2223-1-6

Raghavan, M., Skoglund, P., Graf, K. E., Metspalu, M., Albrechtsen, A., Moltke, I., et al. (2013). Upper Palaeolithic Siberian Genome Reveals Dual Ancestry of Native Americans. Nature, 505, 87-91. http://dx.doi.org/10.1038/nature12736

Reyes-Centeno, H., Ghirotto, S., Detroit, F., Grimaud-Herve, D., Barbujani, G., \& Harvati, K. (2014). Genomic and Cranial Phenotype Data Support Multiple Modern Human Dispersals from Africa and a Southern Route into Asia. Proceedings of the National Academy of Sciences of the United States of America, 111, 7248-7253. http://dx.doi.org/10.1073/pnas.1323666111

Sankararaman, S., Mallick, S., Dannemann, M., Prüfer, K., Kelso, J., Pääbo, S., Patterson, N., \& Reich, D. (2014). The Genomic Landscape of Neanderthal Ancestry in Present-Day Humans. Nature, 507, 354-357. http://dx.doi.org/10.1038/nature12961

Tamura, K., Stecher, G., Peterson, D., Filipski, A., \& Kumar, S. (2013). MEGA6: Molecular Evolutionary Genetics Analysis Version 6.0. Molecular Biology and Evolution, 30, 2725-2729. http://dx.doi.org/10.1093/molbev/mst197

Vernot, B., \& Akey, J. M. (2014). Resurrecting Surviving Neandertal Lineages from Modern Human Genomes. Science, 343, 1017-1021. http://dx.doi.org/10.1126/science.1245938

Winters, C. (2010). The Kushite spread of Haplogroup R1*-M173 from Africa to Eurasia. Current Research Journal of Biological Sciences, 2, 294-299.

Winters, C. (2011). Possible African origin of Y-chromosome R1-M173. International Journal of Science and Nature, 2, 743-745.

Winters, C. (2014). Were the First Europeans Pale or Dark Skinned? Advances in Anthropology, 4, 124-132. http://dx.doi.org/10.4236/aa.2014.43016

Yang, M. A., Malaspinas, A.-S., Durand, E. Y., \& Slatkin, M. (2012). Ancient Structure in Africa Unlikely to Explain Neanderthal and Non-African Genetic Similarity. Molecular Biology and Evolution, 29, 2987-2995.

http://dx.doi.org/10.1093/molbev/mss117 
Scientific Research Publishing (SCIRP) is one of the largest Open Access journal publishers. It is currently publishing more than 200 open access, online, peer-reviewed journals covering a wide range of academic disciplines. SCIRP serves the worldwide academic communities and contributes to the progress and application of science with its publication.

Other selected journals from SCIRP are listed as below. Submit your manuscript to us via either submit@scirp.org or Online Submission Portal.
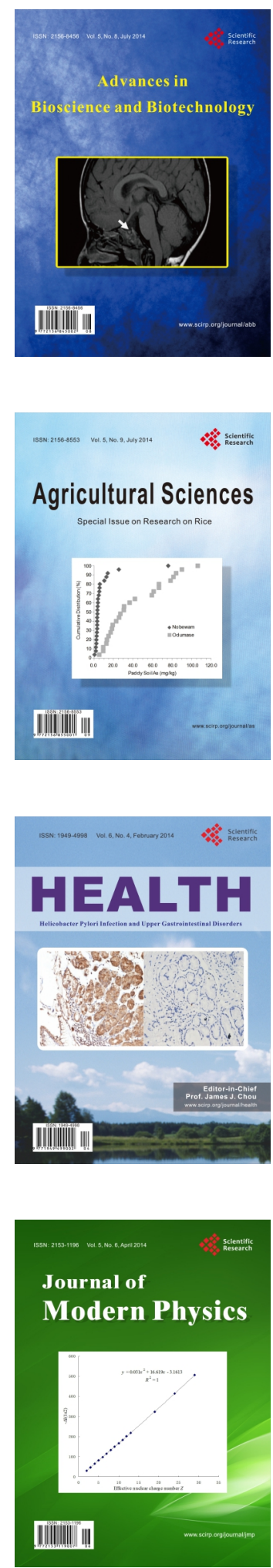
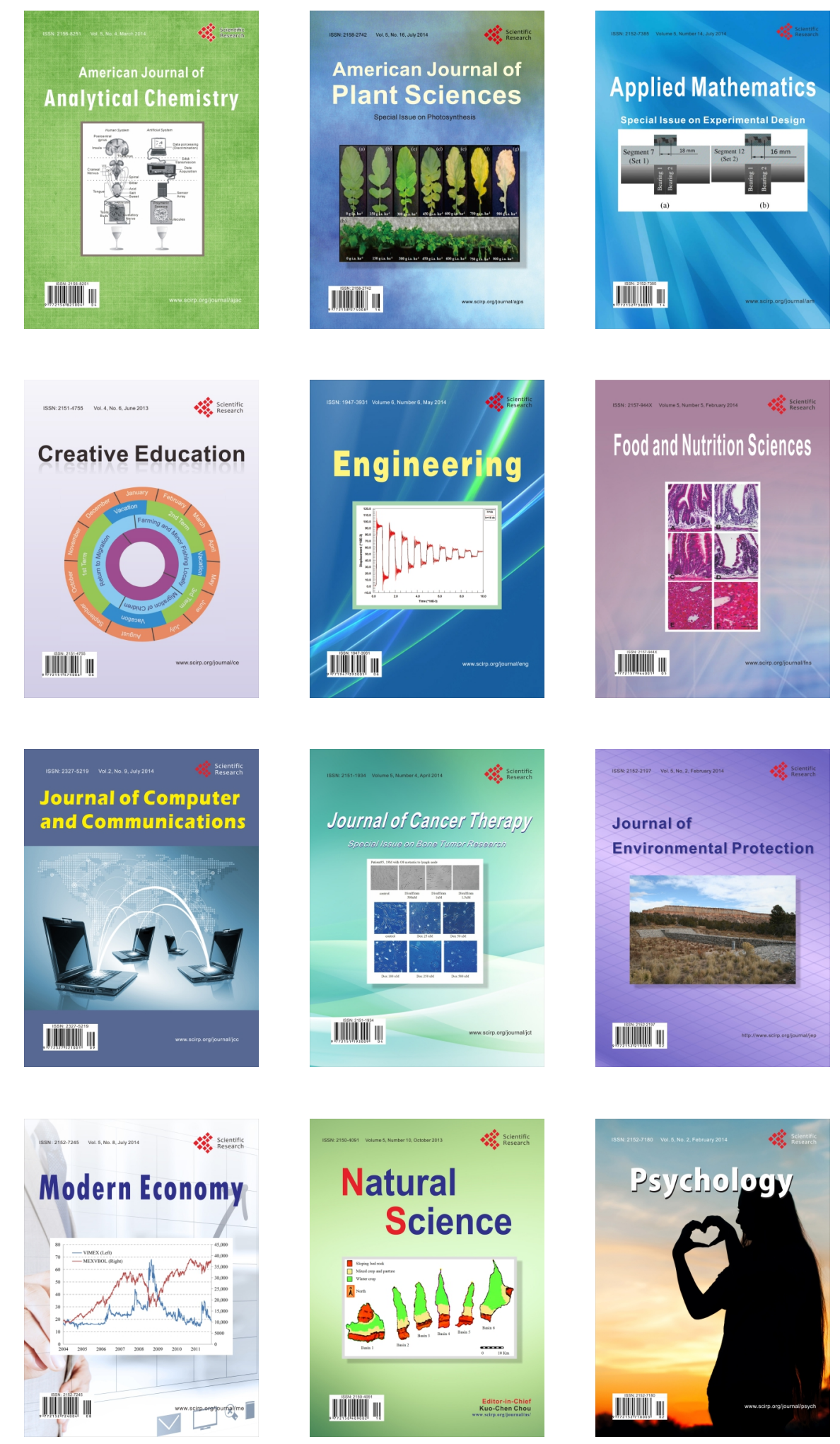